\title{
Impact of sofosbuvir and daclastavir on health-related quality of life in patients co-infected with hepatitis $C$ and human immunodeficiency virus
}

Evy Yunihastuti ${ }^{1,2^{*}} \mathbb{0}$, Fhadilla Amelia ${ }^{2}$, Arini Ika Hapsari ${ }^{2}$, Bramantya Wicaksana ${ }^{2}$, Veritea Natali ${ }^{2}$, Alvina Widhani ${ }^{1,2}$, Andri Sanityoso Sulaiman ${ }^{3}$ and Teguh Harjono Karjadi ${ }^{1,2}$

\begin{abstract}
Background: We conducted a real-life study of health-related quality of life (HRQoL) transformation before and 12 weeks after sofosbuvir and daclatasvir therapy in HCV/HIV co-infected patients. Factors related to the significant changes of each HRQoL domain/item were also evaluated.
\end{abstract}

Methods: A prospective study was performed in the HIV integrated clinic at Cipto Mangunkusumo Hospital, Jakarta. HCV/HIV co-infected patients who started sofosbuvir and daclatasvir from government free DAA program in 20172019. WHOQoL-HIV BREF and RAND SF-36 questionnaires were recorded at baseline and post-treatment week 12.

Results: 145 patients with mean age of 37.8 years $(S D=4.2)$ were included in the analysis. Most of patients were male (89\%), previous IVDU (89\%), active smoker (50.4\%) and non-cirrhosis (80\%). SVR12 was achieved in 95.5\% of patients. Sofosbuvir and daclatasvir treatments showed positive impacts on 2 domains and 2 other items of WHOQoLHIV BREF and 2 domains and 1 item of SF-36. Predicting factors of significant increase in each domain/item were: male and normal body mass index (BMI) for level of independence (RR 4.01,95\% Cl 1.09-14.74 and 4.80,95\% Cl 1.79-12.81); higher HCV-RNA for overall perception of QoL (RR 0.42,95\% Cl 0.18-0.94); non-smoking status for overall perception of health (RR 0.32,95\% Cl 0.15-0.66); male and fibrosis stage 0-1 for general health (RR 6.21,95\% Cl 1.69-22.88 and 2.86,95\% Cl 1.16-7.00); and the use of NNRTI-based ART (RR 5.23, 95\% Cl 1.16-23.65). Spiritual/personal belief decline was predicted by non-smoking status (RR 0.46, 95\% Cl 0.23-0.95). Treatment success was not associated with any changes of HR-QoL domain/item.

Conclusions: HCV/HIV co-infected patients were successfully treated with sofosbuvir and daclatasvir and experienced improvement of HRQOL 12 weeks after treatment completion.

Keywords: Health-related quality of life, Hepatitis C, HCV, HIV, Sofosbuvir, Daclastavir

\footnotetext{
*Correspondence: evy.yunihastuti@gmail.com

1 Allergy and Clinical Immunology Division, Department

of Internal Medicine, Faculty of Medicine, Universitas Indonesia/ Ciptomangunkusumo Hospital, Diponegoro 71, Jakarta, Indonesia

Full list of author information is available at the end of the article
}

\section{Introduction}

$\mathrm{HCV}$ and HIV co-infection is a public health problem affecting more than 2 million people worldwide [1]. Evidence shows that HCV/HIV co-infection cause several negative impacts on the patients, including persistent $\mathrm{HCV}$ viremia, higher $\mathrm{HCV}$ viral load, and faster fibrosis progression [2]. The global use of antiretroviral permits use, sharing, adaptation, distribution and reproduction in any medium or format, as long as you give appropriate credit to the original author(s) and the source, provide a link to the Creative Commons licence, and indicate if changes were made. The images or other third party material in this article are included in the article's Creative Commons licence, unless indicated otherwise in a credit line to the material. If material is not included in the article's Creative Commons licence and your intended use is not permitted by statutory regulation or exceeds the permitted use, you will need to obtain permission directly from the copyright holder. To view a copy of this licence, visit http://creativecommons.org/licenses/by/4.0/. The Creative Commons Public Domain Dedication waiver (http://creativeco mmons.org/publicdomain/zero/1.0/) applies to the data made available in this article, unless otherwise stated in a credit line to the data. 
therapy (ART) has made significant improvements in AIDS-related morbidity and mortality, but for $\mathrm{HCV} / \mathrm{HIV}$ co-infected patients, liver-related mortality remains the common cause of death [3-5]. The reported prevalence of HCV among HIV-infected patients in Indonesia was 17.9\% (95\% CI 15.0-20.5), even higher in intravenous drug user (IVDU) population (81.6\%; 95\% CI 71.1-90.3), indicating that Indonesia has one of the highest rates of $\mathrm{HCV} / \mathrm{HIV}$ co-infection in South East Asia [6].

The World Health Organization (WHO) called for the elimination of viral hepatitis by 2030 via recommendation of hepatitis treatment for all $\mathrm{HCV}$-infected patients, including $\mathrm{HCV} / \mathrm{HIV}$ co-infected patients [7]. The new HCV drugs, direct-acting antivirals (DAAs), has revolutionized the clinical management of $\mathrm{HCV}$-infected patients. The introduction of these drugs has made $\mathrm{HCV}$ the first chronic viral infection that can be cured. This can be achieved in more than $90 \%$ of infected individuals, including $\mathrm{HCV} / \mathrm{HIV}$-coinfected patients, with limited side effects $[8,9]$. Moreover, DAAs also showed promising results in reducing morbidity, mortality, extrahepatic manifestation, and progression to hepatocellular carcinoma [10].

In recent years, health-related quality of life (HRQoL) has gained worldwide recognition as the gold standard of patient-reported outcome (PRO) [11]. The WHO defines HRQoL as an individual's perception of their position in life in the context of the culture and value systems in which they live and in relation to their goals, expectations, standards and concerns". It is a broad-ranging concept affected in a complex way by the person's physical health, psychological state, personal beliefs, social relationships and their relationship to salient features of their environment" [12]. Chronic diseases such as both $\mathrm{HIV}$ and $\mathrm{HCV}$ are strongly related to patients' quality of life. Moreover, HCV infection was related to extrahepatic manifestation that could worsen patient HRQoL and may cause depression in some severe cases, further resulting in disruption of work production and daily activities [13]. The transformation of HRQoL before and after an intervention may help clinicians to understand a patient's perspective. Furthermore, improvement in HRQoL in accordance with patient's well-being may also be related to economical gain $[14,15]$.

Clinical trials of DAAs therapy have exhibited improvement in HRQoL, mostly in HCV mono-infected patients [13, 16-20]. Few studies evaluated HRQoL transformation in HCV/HIV co-infected patients after DAA treatments. HCV/HIV co-infected patients were known to have a lower quality of life and lower QoL gain after DAA treatment $[21,22]$. Furthermore, only limited studies are available on the impact of DAAs on HRQoL in HCV/HIV co-infected patients in real-life settings [22, 23].
In 2017, the Indonesian government started a free DAA program for $\mathrm{HCV}$ mono-infected and $\mathrm{HCV} / \mathrm{HIV}$ co-infected patients, mainly using a combination of sofosbuvir and daclatasvir [24]. Therefore, we conducted a real-life observational study to evaluate HRQoL transformation 12 weeks after treatment completion in HIV and $\mathrm{HCV}$ co-infected patients. To distinguish from other studies, we only recruited patients who were treated with sofosbuvir and daclatasvir. We also evaluated factors related to the significant changes in each HR-QoL domain/item.

\section{Material and methods}

\section{Patients and study design}

This prospective observational study was performed in HIV integrated clinic Cipto Mangunkusumo Hospital Jakarta that provides multidisciplinary $\mathrm{HIV} / \mathrm{HCV}$ care. HCV/HIV-infected patients who started the government's free DAA treatment program between September 2017 and July 2019 were invited to join the study. Eligibility criteria included patients' age more than 18 years old, stable using ART and no active opportunistic infections. Pregnant or breastfeeding women, diagnosis of diabetes mellitus and chronic kidney disease patients were excluded from the study.

\section{HCV treatment}

Non-cirrhotic patients (fibrosis stage $0-3$ ) were treated with oral daily sofosbuvir (400 $\mathrm{mg})$ and daclatasvir (60 or $90 \mathrm{mg}$ ) for 12 weeks while cirrhotic patients (fibrosis stage 4) were treated with daily sofosbuvir and daclatasvir for 24 weeks [10]. Daclatasvir $90 \mathrm{mg}$ was used in patients with efavirenz or nevirapine-based ART and daclatasvir $60 \mathrm{mg}$ in other regimens [25]. Undetectable HCV-RNA 12 weeks after treatment completion was defined as a successful treatment response or sustained virologic response (SVR12) [10].

\section{Data collection}

Sociodemographic variables were collected through personal interviews, and clinical data were collected via medical records in the baseline. Sociodemographic data included in personal interviews were education, marital status, employment status, tobacco use, and mode of $\mathrm{HCV}$ acquisition. Recent $\mathrm{CD} 4^{+}{ }^{+}$-cell counts, ART combination, prior interferon (IFN) treatment failure, Hepatitis B co-infection, hemoglobin levels, and BMI were taken from the patient's medical records. Before starting DAA treatment, all patients were required to have HCV-RNA quantification and fibrosis staging using transient elastography to define the duration of treatment. The following cut-offs were used to stage the 
liver fibrosis: F0-F1<7.1 kPa, F2 7.1-9.4 kPa, F3 9.5$12.4 \mathrm{kPa}$, and $\mathrm{F} 4 \geq 12.5 \mathrm{kPa}[26]$.

HRQoL was measured using the WHO Quality of Life for HIV, in its abbreviated version (WHOQoLHIV BREF) and 36-items RAND Short Form survey (RAND SF-36) before and after treatment completion at 12 weeks $[27,28]$. RAND SF-36, a generic QoL questionnaire that includes eight domains and one question, has widely used as a reference tool to many other studies, making it convenient in comparison with other studies[28]. WHOQOL-HIV BREF is a specified HRQoL instrument utilized for people living with HIV that consisted the evaluation of six domains and two other items [27]. Its ability to capture comprehensive measures of HRQoL differences makes it a suitable tool for our study respondents. We used the Indonesian version of WHOQoL-HIV BREF which had been validated with internal consistency (Cronbach's alpha) of 0.513-0.798 [29]. RAND SF-36 had also been validated into the Indonesian version with the internal consistency of 0.789 and had been previously used in several studies in our HIV clinic [29-31]. All patients were not aware of their final HCV-RNA results before completing these HRQoL questionnaires. Researcher underwent thorough verification to ensure the quality of each data collection. Patients who did not complete the entire course of DAA treatment or post-treatment week 12 evaluation were not included in the analysis.

\section{Statistical analysis}

The data were analysed using the Statistical Package for Social Sciences (SPSS Inc, Chicago, IL) version 20.0 and GraphPad Prism 7 for Windows (GraphPad Software, Inc., La Jolla, CA, USA). Descriptive characteristics were presented with frequency and percentage for categorical variables and mean with SD or median with IQR (Q1-Q3) for continuous variables. Comparative analyses between each QoL component in WHOQoLHIV -BREF and SF-36 were performed using $t$-tests for analyses of variance. Wilcoxon-rank test were used for non-parametric test. The outcome was dichotomized as improved vs not-improved to evaluate the predictors of each improved QoL component. Bivariate analysis was done using Chi-square test. Independent predictors of domain/item improvement were assessed using multivariate logistic regression binary model for all variables that had $p$-value $<0.25$. A $p$-value of less than 0.05 was considered significant and risk ratio (RR) with $95 \% \mathrm{CI}$ was calculated to determine the association.

\section{Results}

Overall, $179 \mathrm{HCV} / \mathrm{HIV}$ co-infected patients were invited to participate before starting DAA treatment between September 2017 to July 2019, 173 of those patients fulfilled the inclusion criteria and signed the informed consent (97\%). At the end of the study, 145 patients completed HCV RNA evaluation and fulfilled both HRQoL evaluation ( $81 \%$ response rate), then were finally analysed (Fig. 1).

\section{Clinical and demographic characteristics}

Baseline demographic and clinical characteristics are summarized in Table 1 . The mean age was 37.8 years $(\mathrm{SD}=4.2)$ and $89 \%$ of patients were male. Previous IVDU represented majority of patients (89\%). About half of patients $(50.4 \%)$ were actively smoking while $45.5 \%$ were previous smokers. Most of the patients were married (58.6\%) and employed (84.2\%). The median duration of ART used was 9 years (IQR 4-12) and median CD4 ${ }^{+}$ T-cell count was 485 cells/ $\mu \mathrm{L}$ (IQR 284-676). Only 13 patients $(9 \%)$ had been treated with previous HCV treatment standard (pegylated interferon and ribavirin combination). None of the patients ever used DAA treatment before. $4.1 \%$ patient were also hepatitis B virus (HBV) coinfected and using tenovofir disoproxil fumarate (TDF). Liver fibrosis degree was F0-F1 in 86 (59.3\%) patients,

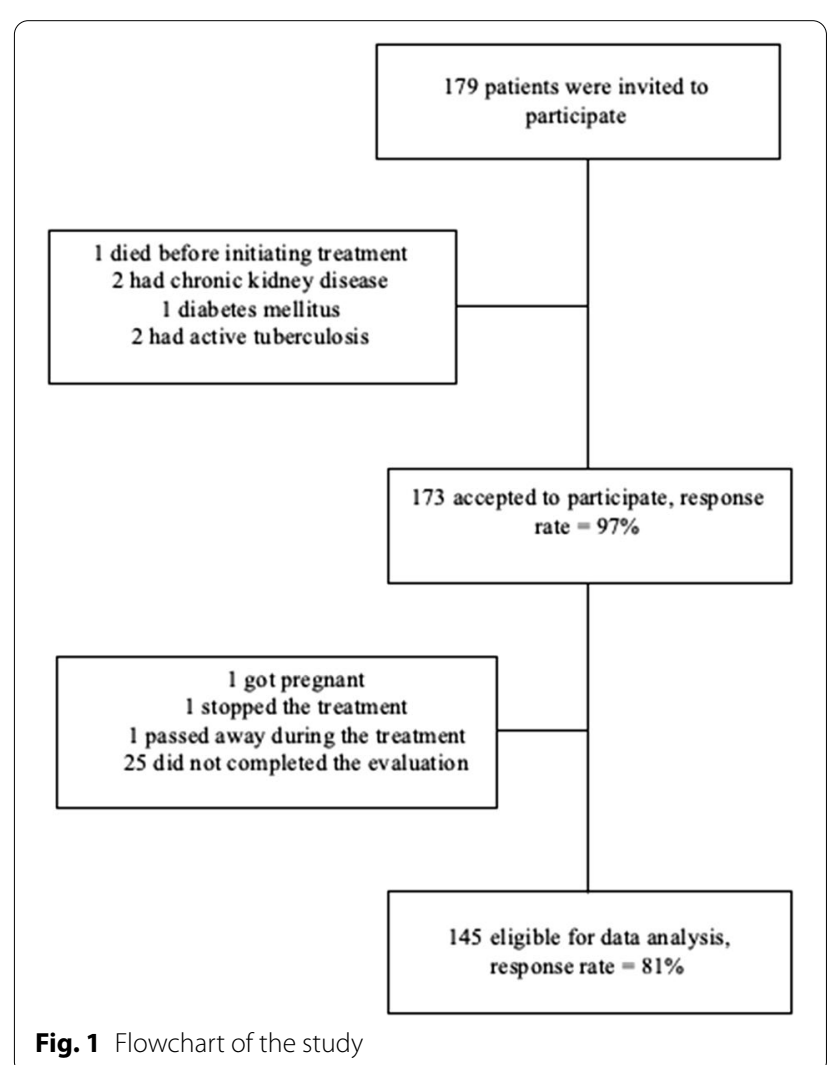


Table 1 Clinical and demographic characteristics

\begin{tabular}{|c|c|}
\hline Characteristics & $N=145$ \\
\hline \multicolumn{2}{|l|}{ Male gender } \\
\hline n (\%) & $129(89.0)$ \\
\hline \multicolumn{2}{|l|}{ Age, years } \\
\hline Mean (SD) & $37.8(4.2)$ \\
\hline \multicolumn{2}{|l|}{ Previous IVDU } \\
\hline$N(\%)$ & $129(89.0)$ \\
\hline \multicolumn{2}{|l|}{ Education } \\
\hline University, n (\%) & $64(44.1)$ \\
\hline Secondary, n (\%) & $79(54.5)$ \\
\hline Primary, n (\%) & $2(1.4)$ \\
\hline \multicolumn{2}{|l|}{ Marital status } \\
\hline Married, n (\%) & $85(58.6)$ \\
\hline Widow/widower/divorce, n (\%) & $22(15.2)$ \\
\hline Not married, n (\%) & $38(26.2)$ \\
\hline \multicolumn{2}{|l|}{ Employment status } \\
\hline Regular employment, $\mathrm{n}(\%)$ & $67(46.2)$ \\
\hline Non-regular employment, n (\%) & $56(38.6)$ \\
\hline Not working, n (\%) & $22(15.2)$ \\
\hline \multicolumn{2}{|l|}{ Religion } \\
\hline Moslem, n (\%) & $114(78.6)$ \\
\hline Christian & $29(20.0)$ \\
\hline Buddhist & $2(1.4)$ \\
\hline \multicolumn{2}{|l|}{ Alcohol use } \\
\hline Active, $\mathrm{n}(\%)$ & $25(17.2)$ \\
\hline Past, n (\%) & $111(76.6)$ \\
\hline Never, n (\%) & $9(6.2)$ \\
\hline \multicolumn{2}{|l|}{ Tobacco use } \\
\hline Active smoker, n (\%) & $73(50.4)$ \\
\hline Past smoker, n (\%) & $66(45.5)$ \\
\hline Never smoke, n (\%) & $6(4.1)$ \\
\hline \multicolumn{2}{|l|}{ BMI } \\
\hline Mean (SD) & $22.3(3.5)$ \\
\hline \multicolumn{2}{|l|}{ Hemoglobin, g/dL } \\
\hline Mean (SD) & $14.9(4.3)$ \\
\hline \multicolumn{2}{|l|}{ Recent CD4 ${ }^{+} \mathrm{T}$ cell count, cells $/ \mu \mathrm{L}$} \\
\hline Median (IQR) & $485(392-675)$ \\
\hline \multicolumn{2}{|l|}{ ART duration, years } \\
\hline Median (IQR) & $9(4-12)$ \\
\hline \multicolumn{2}{|l|}{ ART regimen } \\
\hline NNRTI-based, n (\%) & $126(86.9)$ \\
\hline PI-based, n (\%) & $19(13.1)$ \\
\hline \multicolumn{2}{|l|}{ HBV co-infection } \\
\hline n (\%) & $6(4.1)$ \\
\hline \multicolumn{2}{|l|}{$\mathrm{HCV}$ treatment history } \\
\hline Treatment naïve, n (\%) & $132(91)$ \\
\hline Interferon failure, n (\%) & $13(9)$ \\
\hline \multicolumn{2}{|l|}{ Fibrosis stage } \\
\hline F0-F1, n (\%) & $86(59.3)$ \\
\hline F2-F3, n (\%) & $30(20.7)$ \\
\hline
\end{tabular}

Table 1 (continued)

\begin{tabular}{|c|c|}
\hline Characteristics & $N=145$ \\
\hline F4, n (\%) & $29(20)$ \\
\hline \multicolumn{2}{|l|}{ HCV-RNA, IU/mL } \\
\hline$>800,000, n(\%)$ & $110(75.9)$ \\
\hline$<800,000, \mathrm{n}(\%)$ & $35(24.1)$ \\
\hline Mean (SD), $\log 10$ & $6.22(0.83)$ \\
\hline \multicolumn{2}{|l|}{ HCV genotype } \\
\hline $1, \mathrm{n}(\%)$ & $23(15.8)$ \\
\hline $2, \mathrm{n}(\%)$ & $4(2.8)$ \\
\hline $3, \mathrm{n}(\%)$ & $3(2.1)$ \\
\hline $4, \mathrm{n}(\%)$ & $3(2.1)$ \\
\hline Not available, n (\%) & $112(77.2)$ \\
\hline \multicolumn{2}{|l|}{ DAA combination } \\
\hline SOF + DAC60, n (\%) & $30(20.7)$ \\
\hline SOF + DAC90, n (\%) & $115(79.3)$ \\
\hline \multicolumn{2}{|c|}{ Duration of DAA treatment } \\
\hline 12 weeks, n (\%) & $116(80)$ \\
\hline 24 weeks, n (\%) & $29(20)$ \\
\hline \multicolumn{2}{|l|}{ DAA treatment response } \\
\hline SVR12, n (\%) & $138(95.5)$ \\
\hline Non-responder, n (\%) & $7(4.5)$ \\
\hline
\end{tabular}

F2-F3 in $30(20.7 \%)$ and F4 in $29(20 \%)$ patients. Sofosbuvir with $90 \mathrm{mg}$ daclatasvir was used in majority of the patients (79.3\%). Eighty percents of patients used sofosbuvir and daclatasvir for 12 weeks. Treatment success or SVR12 was achieved in 138 of 145 patients (95.5\%).

\section{Impact of sofosbuvir and daclatasvir treatment to HR-QoL changes}

Sofosbuvir and daclatasvir treatment showed positive impacts on 2 of 6 domains in WHOQoL-HIV BREF (level of independence, environment) and 2 other items (overall perception of quality of life and overall perception of health), but negative impact to 1 domain (spiritual/religion/personal belief) as seen in Fig. 2. Statistically non-significant improvements were observed in the physical and psychological domains. Significant increments were observed in 2 of 8 domains in SF-36 (general health, energy/fatigue), and health change question (Fig. 2). However, domain of pain indicated significant deterioration. We also observed improvements in physical functioning and mental health that were aligned with WHOQoL-HIV BREF assessment, although these domains did not reach statistical significance. In both tools, perception of health shown the highest significant improvement in 12 weeks after the end of treatment. 

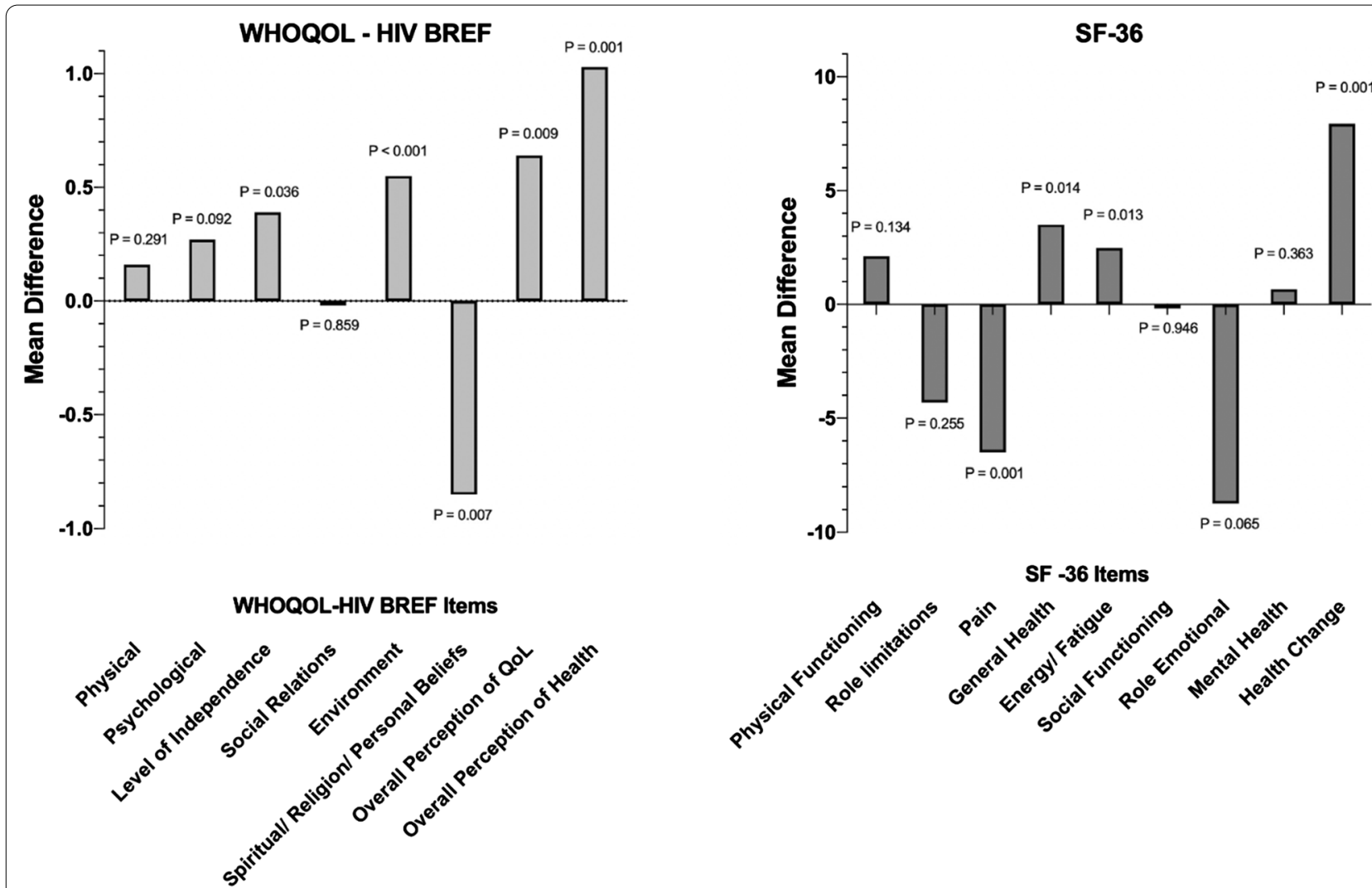

Fig. 2 SVR-12 changes of WHOQOL-HIV BREF and SF-36 in patients with HCV/HIV co-infection. WHOQoL-HIV BREF =World Health Organization Quality of Life Instruments; SF-36= Short Form 36

\section{Factors related to the change in HR-QoL domains/items} Increasing level of independence can be predicted by gender and baseline BMI in WHOQoL-HIV BREF. It increased 4.01 times higher in male patients (95\% CI $1.09-14.74)$ and 4.80 times higher in patients with normal BMI than patients with obesity (95\% CI 1.79-12.81) (Table 2). Higher baseline HCV-RNA independently predicted lower improvement of overall perception of QoL (RR 0.42 , 95\% CI 0.18-0.94). Improvement of overall perception of health was associated with non-smoking status of the patients. It increased 0.32 times lower in non-smoker than smoker (RR 0.32, 95\% CI 0.15-0.66). Non-smoking status was associated with lower spirituality decline (RR 0.46, 95\% CI 0.23-0.95), and the use of non-nucleoside reverse transcriptase inhibitor (NNRTI)based ART was associated with higher increase in spirituality domain compared to PI-based regimen (RR 5.25, 95\% CI 1.16-23.65). We did not find any factor that can predict improvement of environmental component.

Male patients exhibited 6.21 times higher general health increase than female patients (95\% CI 1.69-22.88) (Table 3). Patients with fibrosis stage $0-1$ indicated 2.85 times higher general health increase than those with fibrosis stage 4 (95\% CI 1.16-7.00). We did not find any significant predictor of improvement of energy and health change, nor predictor of pain worsening in this study. Only history of interferon failure showed a better trend of health change improvement (RR 3.09, 95\% CI 0.96-10.01).

Sustained virologic response-achievers and nonresponders did not reach significant change on any domain/item of HR-QoL in both questionnaires.

\section{Discussion}

Our study is one of few cohorts evaluating impact of DAA treatment in quality of life of $\mathrm{HCV} / \mathrm{HIV}$ co-infected patients. Early on, improved HRQoL was shown to be associated with a SVR of IFN-based treatment that has high toxicity, more complexity and lower treatment uptake in many low-middle income countries [32]. In $\mathrm{HCV} / \mathrm{HIV}$ co-infected patients, SVR rates are historically 20-30\% lower than in HCV mono-infected patients [33]. The introduction of interferon-free DAA treatment has been a significant breakthrough since this combination is likely to close the gap of SVR between HCV/HIV coinfection and HCV mono-infection $[8,9]$. 


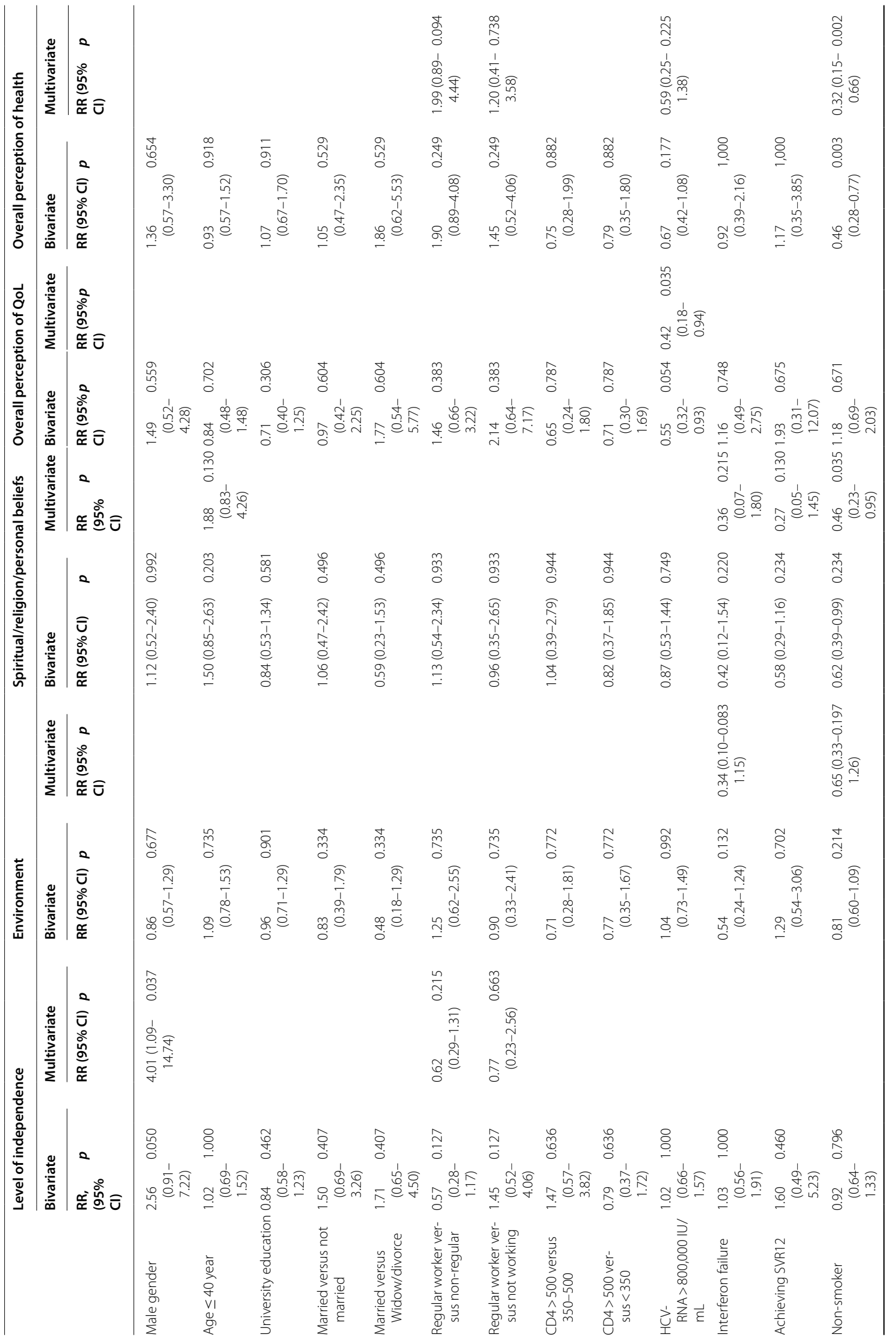




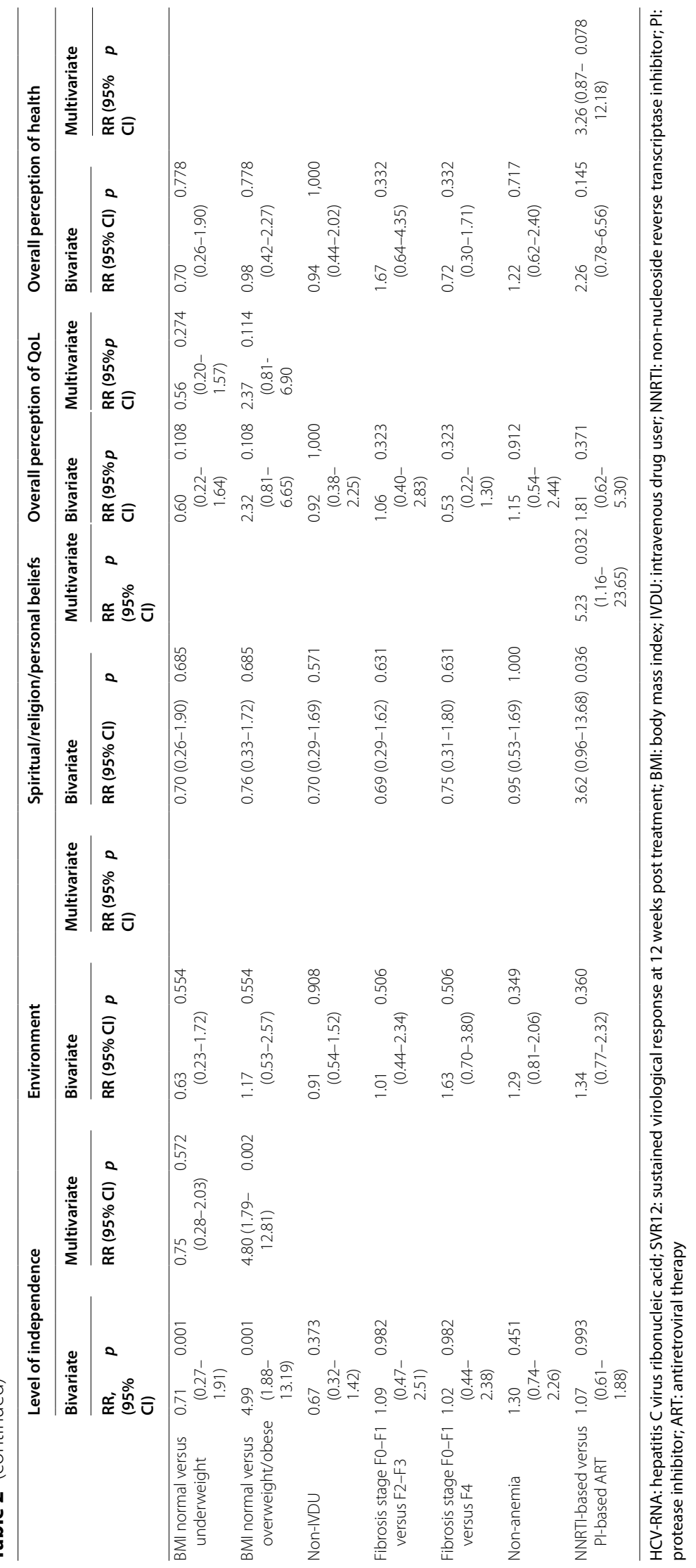




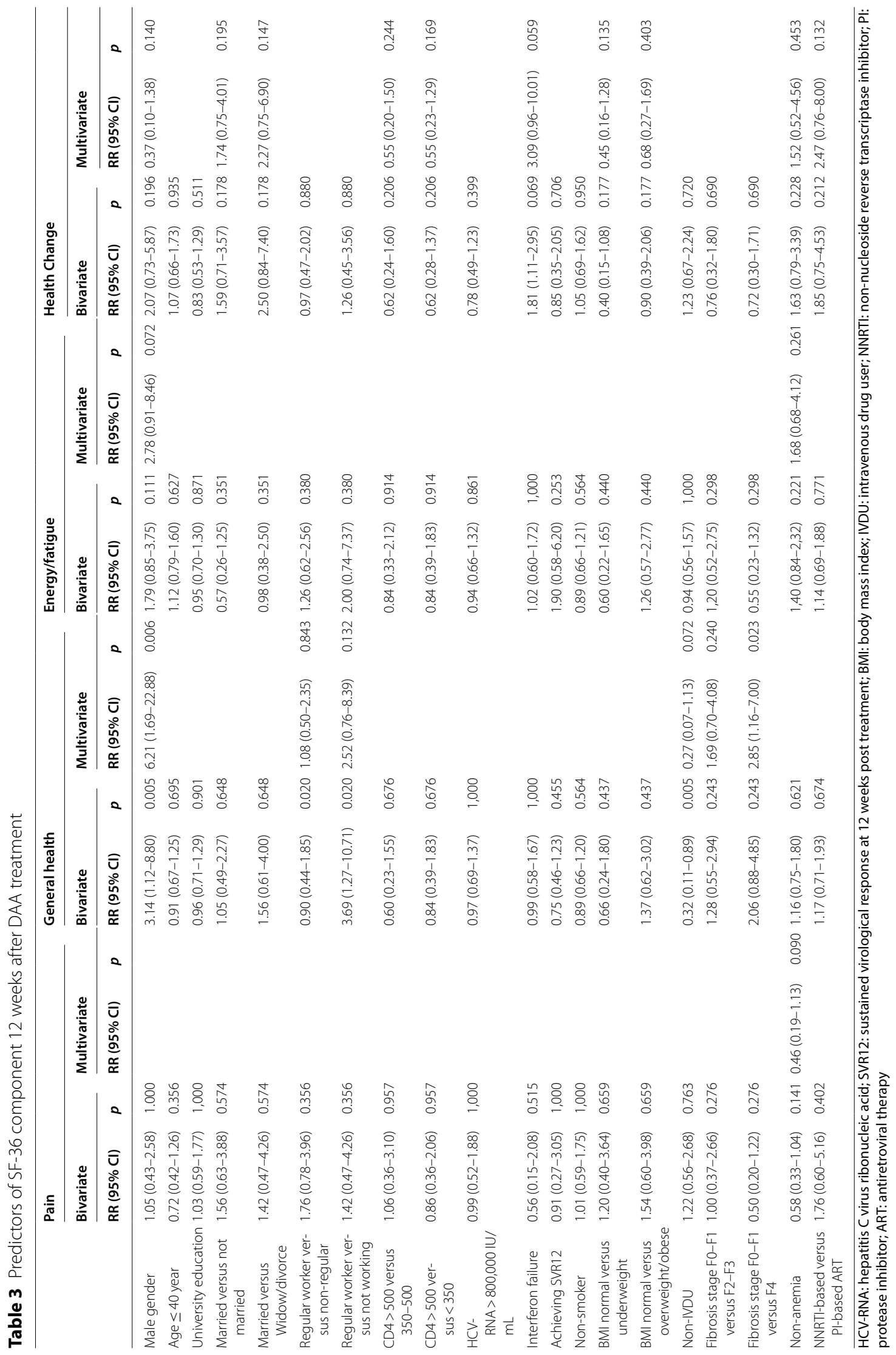


Results from clinical trials of DAA treatments have shown improvements in the physical and psychological components of HRQoL, mostly in HCV mono-infected patients [16, 19, 34]. Many clinicians were concerned that clinical trial results cannot be generalized to realworld situations due to the studies' strict selection criteria [35]. Several researchers have attempted to investigate the impact of DAA treatments on HR-QoL of HCV/HIV co-infected patients, with various treatment combinations and tools, with conflicting results [13, 23, 34, 36]. In studies comparing $\mathrm{HCV}$ mono-infected and $\mathrm{HCV} /$ HIV co-infected patients, HCV/HIV co-infected patients were associated with significantly lower HR-QoL and lower gain in the HR-QoL scores [21, 22]. Our study design aimed to inform real-world impact of sofosbuvir and daclatasvir combination treatment in a younger and mainly former IVDU population.

We found that the improvements were observed across many HR-QoL domains/items in both WHOQOL-HIV BREF and SF-36. This finding provides additional evidence that DAA treatment has a positive influence on $\mathrm{HCV} / \mathrm{HIV}$ co-infected patients on ART [13, 23, 34, 36, 37]. Improvements were not observed in some domains when comparing 12 weeks after treatment scores with baseline scores. Longer study duration and more followup timepoints could show potential benefits in more domains.

Using multivariate analyses, we determined several baseline predictors of several WHOQoL-HIV BREF domain/item changes 12 weeks after treatment completion. We found that male patients had improved their level of independence 4 times higher than female patients after DAA treatment, which is consistent with previous studies in male HIV patients [38-40]. Most female patients in our study were married and not working despite being highly educated. Tesfay et al. showed that monthly income was an independent predictor of poor HR-QoL among female HIV patients [41]. We also found that having normal BMI was associated with better improvement in level of independence compared to being overweight/obese. This result is aligned with a study in Southern Ethiopia that showed normal BMI significantly improved QoL score of HIV-infected patients. Protection from infectious diseases, improvement of health status, and the ability to live a productive life are promoted by better nutritional status [42]. Moreover, people with obesity have higher risk of having mobility disability, eventuating a higher risk of becoming unemployed [43, 44].

Lower improvement of overall perception of QoL was noticed in patients with higher baseline HCV-RNA. $\mathrm{HCV}$ viremia has been associated with depression and fatigue [45]. Younossi et al. found that in $\mathrm{HCV} / \mathrm{HIV}$ coinfected patients, continuous viremia was associated with substantial impairment in QoL [34]. However, we did not observe differences of any HR-QoL changes in SVR responders compared to non-responders. All patients were well-informed of the high success rate of these expensive but free drugs. Though the final questionnaires were delivered before HCV-RNA results came out, many patients were confident of their treatment success. Yeung et al. demonstrated that those achieving an SVR had higher HR-QoL scores over time. Only 38\% participants in that study achieved SVR, 30\% did not respond, $13 \%$ had ongoing treatment, and $17 \%$ had unknown treatment response [37]. Our study had a much higher treatment response (95.5\%), but the shorter period of HR-QoL evaluation might be insufficient. A longer duration of evaluation might be needed to see further impact of SVR as another study with high treatment response found modest immediate improvement following SVR, then continued thereafter [37].

The overall perception of health significantly improved after treatment in our study, but interestingly the improvement was more remarkable among smokers. Our finding contradicted another study that showed overall QoL among current and past smokers was relatively lower than non-smokers [46]. A possible explanation that smokers had disparaging behavior towards the relative risk of smoking to their health [47]. Apart from that, highly successful DAA treatment beliefs might influence our participants' perception of health and spirituality when they filled in their final questionnaires since patients did not know their HCV-RNA results yet. As these patients had used ART for a median of 9 years and had known the impact of their untreated HCV status for a long time, completing DAA treatment would be considered a morbidity risk reduction for these patients despite their smoking status.

We also observed a higher reduction in the spiritual/ religion/personal belief domain in smokers. Evidence has shown that smoking behavior was significantly related to religious involvement (religious attendance, importance, religious/spiritual comfort-seeking, and religious/spiritual decision-making). Higher religious involvement is linked with a lower risk of being current or past smoker [48]. Islam as a dominant religion among participants (78.6\%) might also play a role in this finding as smoking is considered as a discouraged act (mukrooh) in Islamic law [49]. Once these patients finished DAA treatment course, they might have reduced their religious involvement.

In Indonesia, NNRTIs (efavirenz and nevirapine) were used as the first line-ART regimen, and PI is used as the second line-ART regimen. The only PI used in our study was lopinavir/ritonavir, bigger size and higher burden of pills than NNRTI. The use of second-line ART indicates that the patients had experienced immunological and/ 
or virological failure, which might impact their spiritual condition. Improvement of quality of life was also shown in an earlier study that evaluated HIV-infected patients who switch antiretroviral medication from PI to efavirenz [50].

We proceeded to determine baseline predictors of several SF-36 domain/item changes 12 weeks after treatment completion in the studied population. Similar to other reports, we demonstrated a significant rise in the general health domain [34, 51]. Positive relationships between general health increase with male gender and stage F0-F1 fibrosis were also noticed. This gender association was in line with the level of independence domain in WHOQoL-HIV BREF. Younossi et al. also confirmed a similar increase of general health among stage F0-F1 fibrosis in $\mathrm{HCV}$ mono-infected patients treated with sofosbuvir and ledipasvir [52].

\section{Limitations}

There are several limitations to our study. Firstly, the study was done in a tertiary center and the population size was not large enough to acquire conclusive results of certain subanalyses. However, we were able to evaluate $81 \%$ of the patients who received treatment during the study period. Since it was done in the early phase of free DAA treatment program in Indonesia, we believe that these encouraging results would endorse the expansion of the program. Secondly, we only used WHOQoL-HIV BREF and RAND SF-36 whereas many studies use multiple instruments [53-57]. Moreover, we did not evaluate depression and anxiety as other factors that could be potentially related to QoL.

Despite those limitations, our study could give a standing point for future research on QoL studies and health outcome improvement among HCV/HIV co-infected patient. These findings provide information about QoL and some influencing factors among $\mathrm{HCV} / \mathrm{HIV}$ coinfected patients in Indonesia where studies in these cohorts are still limited.

\section{Conclusions}

In summary, our study indicates that treatment with sofosbuvir and daclatasvir is associated with improvement of quality of life 12 weeks after treatment completion in HCV/HIV co-infected patients. Our data support the fact that treating $\mathrm{HCV}$, including in HIV co-infected patients, will lead to substantial PRO improvement in addition to the possibility of curing HCV. Expanding free access to this simple and highly active treatment is important for HIV-infected patients on ART.

\section{Abbreviations}

HRQOL: Health-related quality of life; DAA: Direct-acting antiviral; IVDU: Intravenous drug user; WHOQOL-HIV BREF: WHO quality of life for HIV; ART : Antiretroviral therapy; PRO: Patient-reported outcome; SVR12: Sustained virological response at 12 weeks post treatment; IFN: Interferon; RAND SF-36: 36-Items RAND short form survey; TDF: Tenovofir Disoproxil Fumarate; NNRTI: Non-nucleoside reverse transcriptase inhibitor; PI: Protease inhibitor.

\section{Acknowledgements}

The authors thank Salfia Lastari and Utami Susilawati for their statistical analysis, Jacquita Suemarni Affandi for the valuable input, Madyaningati, all HIV integrated center staffs, and all patients who participated in the study.

\section{Authors' contributions}

EY, AW, ASS designed the study. EY, FA, VN, AW, ASS, THK collected and managed the data. EY, FA, AlH, BW performed statistical analysis and draft the manuscript. EY was a major contributor in writing the manuscript. All authors read and approved the final manuscript.

\section{Funding}

Not applicable.

\section{Availability of data and materials}

The datasets used and/or analysed during the current study are available from the corresponding author on reasonable request.

\section{Declarations}

Ethics approval and consent to participate

Ethics Committee at the Faculty of Medicine Universitas Indonesia approved the study before initiation. Each participant gave their written informed consent after explanation of the study procedure and purpose. Permission was given for the collection of medical data from medical records. Trained researchers were available to assist when needed.

\section{Consent for publication}

Not applicable.

\section{Competing interests}

The authors declare that they have no competing interests.

\section{Author details}

${ }^{1}$ Allergy and Clinical Immunology Division, Department of Internal Medicine, Faculty of Medicine, Universitas Indonesia/Ciptomangunkusumo Hospital, Diponegoro 71, Jakarta, Indonesia. ${ }^{2}$ HIV Integrated Services, Ciptomangunkusumo Hospital, Jakarta, Indonesia. ${ }^{3}$ Hepatobilliary Division, Department of Internal Medicine, Faculty of Medicine, Universitas Indonesia, Jakarta, Indonesia.

Received: 11 December 2020 Accepted: 21 April 2021

Published online: 26 May 2021

References

1. Platt L, Easterbrook P, Gower E, Al E. Prevalence and burden of HCV co-infection in people living with HIV: a global systematic review and meta-analysis. Lancet Infect Dis. 2016;16:797-808.

2. Hernandez, MD. Sherman K. HIV/HCV coinfection natural history and disease progression, a review of the most recent literature. Curr Opin HIV AIDS 2011; 6: 478-82.

3. Smith CJ, Ryom L, Weber R, Morlat P, Pradier C, Reiss P, et al. Trends in underlying causes of death in people with HIV from 1999 to 2011 (D:A:D): a multicohort collaboration. Lancet. 2014;384:241-8.

4. Croxford S, Kitching A, Desai S, Kall M, Edelstein M, Skingsley A, et al. Mortality and causes of death in people diagnosed with HIV in the era of highly active antiretroviral therapy compared with the general population: an analysis of a national observational cohort. Lancet public Heal. 2017;2:35-46. 
5. Hernando V, Perez-Cachafeiro S, Lewden C, Gonzalez J, Segura F, Oteo $J A$, et al. All-cause and liver-related mortality in HIV positive subjects compared to the general population: differences by HCV co-infection. J Hepatol. 2012;57:743-51.

6. Martinello M, Amin J, Matthews GV, Dore GJ. Prevalence and disease burden of HCV coinfection in HIV cohorts in the Asia pacific region: a systematic review and meta-analysis. AIDS Rev. 2016;18:69-80.

7. World Health Organization. Hepatitis C. https://www.who.int/en/newsroom/fact-sheets/detail/hepatitis-c.

8. Chung RT, Baumert TF. Curing chronic hepatitis $C$-the arc of a medical triumph. N Engl J Med. 2014;370:1576-8.

9. Abutaleb A, Sherman KE. A changing paradigm: management and treatment of the HCV/HIV-co-infected patient. Hepatol Int. 2018;12:500-9.

10. World Health Organization. Guidelines for the care and treatment of persons diagnosed with chronic hepatitis C virus infection. Geneve: WHO; 2018.

11. Bullinger M, Quitmann J. Quality of life as patient-reported outcomes: principles of assessment. Dialogues Clin Neurosci. 2014;16:137-45.

12. World Health Organization. WHOQOL: measuring quality of life. https:// www.who.int/healthinfo/survey/whogol-qualityoflife/en/.

13. Younossi ZM, Stepanova M, Sulkowski M, Naggie S, Henry L, Hunt S. Sofosbuvir and ledipasvir improve patient-reported outcomes in patients co-infected with hepatitis $C$ and human immunodeficiency virus. J Viral Hepat. 2016;23:857-65.

14. Groen WG, Kuijpers W, Oldenburg HS, Wouters MW, Aaronson NK, van Harten WH. Supporting lung cancer patients with an interactive patient portal: feasibility study. JMIR Cancer. 2017;3:e10

15. Muragundi P, Tumkur A, Shetty R, Naik A. Health-related quality of life measurement. J Young Pharm. 2012;4:54.

16. Younossi ZM, Henry L. Systematic review: patient-reported outcomes in chronic hepatitis $\mathrm{C}$ - the impact of liver disease and new treatment regimens. Aliment Pharmacol Ther. 2015;41:497-520.

17. Younossi ZM, Stepanova M, Nader F, Jacobson IM, Gane E, Nelson D, et al. Patient-reported outcomes in chronic hepatitis $C$ patients with cirrhosis treated with sofosbuvir-containing regimens. Hepatology. 2014;59:2161-9.

18. Stepanova M, Nader F, Cure S, Bourhis F, Hunt S, Younossi Z. Patients' preferences and health utility assessment with SF-6D and EQ-5D in patients with chronic hepatitis $C$ treated with sofosbuvir regimens. Aliment Pharmacol Ther. 2014;40:676-85.

19. Younossi ZM, Stepanova M, Feld J, Zeuzem J, Jacobson I, Agarwal K, et al. Sofosbuvir/velpatasvir improves patient-reported outcomes in HCV patients: results from ASTRAL-1 placebo-controlled trial. J Hepatol. 2016;65:33-9.

20. Younossi ZM, Stepanova M, Sulkowski M, Foster GR, Reau N, Mangia A, et al. Ribavirin-free regimen with sofosbuvir and velpatasvir is associated with high efficacy and improvement of patient-reported outcomes in patients with geno- types 2 and 3 chronic hepatitis C: results from Astral-2 and -3 clinical trials. Clin Infect Dis. 2016;63:1042-8.

21. Pereira M, Fialho R. Assessment of factors associated with the quality of life of patients living with HIV/HCV co-infection. J Behav Med. 2016;39:767-81.

22. Goñi-Esarte S, Juanbeltz R, Martínez-Baz I, Castilla J, Miguel RS, Herrero $\mathrm{Jl}$, et al. Long-term changes on health-related quality of life in patients with chronic hepatitis $C$ after viral clearance with direct-acting antiviral agents. Rev Esp Enfermedades Dig. 2019;111:445-52.

23. Scheiner B, Schwabl P, Steiner S, Bucsics T, Chromy D, Aichelburg $M C$, et al. Interferon-free regimens improve health-related quality of life and fatigue in HIV/HCV-coinfected patients with advanced liver disease. Medicine. 2016;95:1-8.

24. World Health Organization. Progress report on access to hepatitis $C$ treatment. Focus on overcoming access barriers: experiences of selected countries. 2018. https://www.who.int/hepatitis/publications/ hep-c-access-report-2018/en/.

25. Bifano M, Hwang C, Oosterhuis B, Hartstra J, Grasela D, Tiessen R, et al. Assessment of pharmacokinetic interactions of the HCV NS5A replication complex inhibitor daclatasvir with antiretroviral agents: ritonavir-boosted atazanavir, efavirenz and tenofovir. Antivir Ther. 2013;18:931-40.

26. Truong TN, Laureillard D, Lacombe K, Thi HD, Hanh PPT, Xuan LTT, et al. High proportion of HIV-HCV coinfected patients with advanced liver fibrosis requiring hepatitis $C$ treatment in Haiphong, Northern Vietnam. PLOS ONE. 2016;11:1-13.

27. World Health Organization. WHOQOL-HIV Instrument Users Manual. 2002.

28. Ware JE, Gandek B. Overview of the SF-36 health survey and the international quality of life assessment (IQOLA) project. J Clin Epidemiol. 1998;51:903-12.

29. Muhammad NN, Shatri H, Djoerban Z, Abdullah M. Uji kesahihan dan keandalan kuesioner World Health Organization Quality of Life-HIV Bref dalam bahasa indonesia untuk mengukur kualitas hidup pasien HIV/AIDS. J Penyakit Dalam Indones. 2017;4:112.

30. Salim S, Yamin M, Alwi I, Setiati S. Validity and reliability of the Indonesian version of SF-36 quality of life questionnaire on patients with permanent pacemakers. Acta Medica Indones. 2017;49:10-6.

31. Astoro NW, Djauzi S, Djoerban Z, Prodjosudjadi W. Quality of life of HIV patients and influential factors. Acta Med Indones. 2007;39:2-7.

32. Bonkovsky HLWJ. Reduction of health-related quality of life in chronic hepatitis $\mathrm{C}$ and improvement with interferon therapy. The Consensus Interferon Study Group. Hepatology. 1999;29:264-70.

33. Torriani FJ, Rodriguez-Torres M, Rockstroh JK, Lissen E. Peginterferon Alfa-2a plus ribavirin for chronic hepatitis C virus infection in HIV- infected patients. N Engl J Med. 2004;351:438-50.

34. Younossi ZM, Stepanova M, Sulkowski M, Wyles D, Kottilil S, Hunt S. Patient-reported outcomes in patients co-infected with hepatitis $C$ virus and human immunodeficiency virus treated with sofosbuvir and velpatasvir: the ASTRAL-5 study. Liver Int. 2017;37:1796-804.

35. Saeed S, Strumpf EC, Walmsley SL, Rollet-Kurhajec K, Pick N, Martel-Laferrière $V$, et al. How generalizable are the results from trials of direct antiviral agents to people coinfected with HIV/HCV in the real world? Clin Infect Dis. 2016;62:919-26.

36. Yeung MW, Young J, Moodie E, Rollet-Kurhajec KC, Schwartzman K, Greenaway $C$, et al. Changes in quality of life, healthcare use, and substance use in HIV/hepatitis $C$ coinfected patients after hepatitis $C$ therapy: a prospective cohort study. HIV Clin Trials. 2015;16:100-10.

37. Saeed S, Moodie EEM, Strumpf E, Gill J, Wong A, Cooper C, et al. Real-world impact of direct acting antiviral therapy on health-related quality of life in HIV/Hepatitis C co-infected individuals. J Viral Hepat. 2018:25:1507-14.

38. Bakiono F, Ouédraogo L, Sanou M, Samadoulougou S, Kirakoya-Samadoulougou PWLGF, Robert A. Quality of life in people living with HIV: a cross-sectional study in Ouagadougou, Burkina Faso. Springerplus 2014; 3: 372.

39. Nobre N, Pereira M, Roine RP, Sintonen H, Sutinen J. Factors associated with the quality of life of people living with HIV in Finland. AIDS Care. 2017;29:1074-8.

40. Arjun BY, Unnikrishnan B, Ramapuram JT, Thapar R, Mithra P, Kumar N, et al. Factors influencing quality of life among people living with HIV in Coastal South India. J Int Assoc Provid AIDS Care. 2015;16:247-53.

41. Tesfay A, Gebremariam A, Gerbaba M, Abrha H. Gender differences in health related quality of life among people living with HIV on highly active antiretroviral therapy in Mekelle Town, Northern Ethiopia. Biomed Res Int. 2015. https://doi.org/10.1155/2015/516369.

42. Tesemma AL, Abate MG, Abebo ZH, Madebo WE. Determinants of poor quality of life among adults living with HIV and enrolled in highly active antiretroviral therapy at public health facilities of Arba Minch Town Administration in Southern Ethiopia. HIV AIDS. 2019;11:387-94.

43. de Munter JS, Tynelius P, Ahlström G, Rasmussen F. The bidirectional association between body weight and mobility disability: a population-based cohort. Disabil Health J. 2016;9:632-7.

44. Norrbäck M, Tynelius P, Ahlström G, Rasmussen F. The association of mobility disability and obesity with risk of unemployment in two cohorts from Sweden. BMC Public Health. 2019;19:347.

45. Thein H-H, Butler T, Krahn M, Rawlinson W, Levy MH, Kaldor JM, et al. The effect of hepatitis $C$ virus infection on health-related quality of life in prisoners. J Urban Heal. 2006;83:275-88.

46. Toghianifar N, Najafian J, Pooya A, Rabiei K, Eshrati B, Anaraki J, et al. Association of smoking status with quality of life in a cross-sectional population-based sample of iranian adults: Isfahan healthy heart program. Asia-Pacific J Public Heal. 2012;24:786-94. 
47. Krosnick JA, Malhotra N, Mo CH, Bruera EF, Chang LC, Pasek J, et al. Perceptions of health risks of cigarette smoking: a new measure reveals widespread misunderstanding. PLoS ONE. 2017;12:1-23.

48. Bailey ZD, Slopen N, Albert M, Williams DR. Multidimensional religious involvement and tobacco smoking patterns over 9-10 years: a prospective study of middle-aged adults in the United States. Soc Sci Med. 2015;138:128-35.

49. Ghouri N, Atcha M, Sheikh A. Influence of Islam on smoking among Muslims. BMJ Clin Res. 2006:332:291

50. Campo RE, Cohen C, Grimm K, Shangguan T, Maa J, Seekins D. Switch from protease inhibitor- to efavirenz-based antiretroviral therapy improves quality of life, treatment satisfaction and adherence with low rates of virological failure in virologically suppressed patients. Int J STD AIDS. 2010;21:166-71.

51. Younossi ZM, Stepanova M, Omata M, Mizokami M, Walters M, Hunt S. Quality of life of Japanese patients with chronic hepatitis C treated with ledipasvir and sofosbuvir. Medicine. 2016;95:1-7.

52. Younossi ZM, Stepanova M, Afdhal N, Kowdley KV, Zeuzem S, Henry L, et al. Improvement of health-related quality of life and work productivity in chronic hepatitis C patients with early and advanced fibrosis treated with ledipasvir and sofosbuvir. J Hepatol. 2015;63:337-45.

53. Ichikawa T, Miyaaki H, Miuma S, Taura N, Motoyoshi Y, Akahoshi H, et al. Hepatitis C virus-related symptoms, but not quality of life, were improved by treatment with direct-acting antivirals. Hepatol Res. 2018;48:232-9.
54. Pereira L, De MJ, Barreto M, Lima C, Maria M, Pires A, et al. Treatment with sofosbuvir and daclatasvir (with or without ribavirin) improves patient reported outcomes in hepatitis C. Osong Public Heal Res Perspect. 2018;9:50-8.

55. Younossi ZM, Stepanova M, Esteban R, Jacobson I, Zeuzem S, Sulkowski $M$, et al. Superiority of interferon-free regimens for chronic hepatitis C. Medicine (Baltimore). 2017;96:e5914.

56. Younossi ZM, Stepanova M, Feld J, Zeuzem S, Sulkowski M, Foster GR, et al. Sofosbuvir and velpatasvir combination improves patient-reported outcomes for patients with HCV infection, without or with compensated or decompensated cirrhosis. Clin Gastroenterol Hepatol. 2017;15:421-30. e6.

57. Doyle JS, Grebely J, Spelman T, Alavi M, Matthews G, Thompson AJ, et al. Quality of life and social functioning during treatment of recent hepatitis C infection: a multi-centre prospective cohort. PLOS ONE. 2016;11:1-16.

\section{Publisher's Note}

Springer Nature remains neutral with regard to jurisdictional claims in published maps and institutional affiliations.
Ready to submit your research? Choose BMC and benefit from:

- fast, convenient online submission

- thorough peer review by experienced researchers in your field

- rapid publication on acceptance

- support for research data, including large and complex data types

- gold Open Access which fosters wider collaboration and increased citations

- maximum visibility for your research: over 100M website views per year

At BMC, research is always in progress.

Learn more biomedcentral.com/submissions 